\title{
Deteksi Dini Retinopati Diabetik dengan Pengolahan Citra Berbasis Morfologi Matematika
}

\author{
Lukman Heryawan \\ Departemen Ilmu Komputer dan Elektronika, FMIPA UGM, Yogyakarta \\ e-mail: Lukmanh@ugm.ac.id
}

\begin{abstract}
Abstrak
Retinopati diabetik merupakan komplikasi yang diakibatkan oleh diabetes melitus. Retinopati diabetik jika tidak ditangani dengan tepat dapat mengakibatkan kebutaan. Langkah penting untuk mencegah kebutaan adalah deteksi dini. Deteksi dini dapat dilakukan dengan menemukan gejala awal yakni microaneurysm. Pada penelitian ini dibuat sistem untuk mendeteksi retinopati diabetik dengan menggunakan algoritma deteksi microaneurysm dengan morfologi matematika. Algoritma terbagi menjadi tiga tahap yakni preprocessing, menentukan kandidat microaneurysm dan postprocessing. Pada penelitian ini sistem akan dibuat dengan menggunakan raspbery pi sebagai medianya. Untuk melihat seberapa baik kemampuan sistem mendeteksi retinopati diabetik dilakukan pengujian. Pengujian sistem dilakukan dengan menggunakan data citra fundus mata dari DIARETDB1 dan e-optha. Pada pengujian yang dilakukan diperoleh hasil dengan akurasi $86,51 \%$, sensitivitas $90,00 \%$ dan spesifitas $55 \%$ menggunakan data dari DIARETDB1. Sedangkan pengujian menggunakan data dari e-optha diperoleh hasil dengan akurasi 70,5\%, sensitivitas $80 \%$ dan spesifitas $60 \%$.
\end{abstract}

Kata kunci-Retinopati diabetik, microaneurysm, morfologi matematika

\begin{abstract}
Diabetic retinopathy is a complication caused by diabetes mellitus. Diabetic retinopathy, if not handled properly can lead to blindness. A necessary step to prevent blindness is early detection. Early detection can be done by finding the initial symptoms that microaneurysm. In this research, a system made to detect diabetic retinopathy using algorithms detection microaneurysm with mathematical morphology. The algorithm is divided into three stages of preprocessing, detecting candidate microaneurysm and postprocessing. In this research, the system will be made by using a raspberry pi as the media. To see how well the system detects diabetic retinopathy, the test will be done. in the tests performed, system obtained an accuracy of $90 \%$, sensitivity 90 , and specificity of $55 \%$ using data diaretdb1. While testing using data from e-ophtha obtained results with an accuracy of 70.5\%, a sensitivity of $80 \%$ and a specificity of $60 \%$.
\end{abstract}

Keywords-Diabetic retinopathy, microaneurysm, mathematical morphology

\section{PENDAHULUAN}

$\mathrm{D}$ abetes Melitus atau Diabetes merupakan salah satu penyakit kronik degeneratif yang memiliki angka morbiditas dan mortalitas yang tinggi [1]. Hal ini dikarenakan penderita diabetes memiliki resiko yang tinggi untuk memunculkan banyak masalah kesehatan. Pasien yang menderita diabetes dalam jangka panjang berisiko mengalami hilangnya penglihatan atau kebutaan, yang disebabkan oleh darah dari pembuluh darah yang bocor ke retina [2]. Komplikasi diabetes ini disebut dengan retinopati diabetik. 
Beberapa tahun terakhir, Retinopati diabetik menjadi penyebab umum kebutaan pada penderita diabetes [3]. Selain itu Retinopati diabetik juga menjadi penyebab baru kebutaan pada orang dewasa pada usia kerja di dunia Industri [3]. Hal ini terjadi dikarenakan banyak orang dewasa pada usia kerja telah menderita penyakit diabetes. Di poli mata RSUP Dr.Sardjito Yogyakarta pasien yang mengalami gangguan mata akibat diabetes melitus cukup tinggi, yakni antara 40-50 pasien setiap hari. Sedangkan kasus kebutaan mencapai $10 \%$.

Masalah utama dalam penanganan retinopati diabetik adalah keterlambatan diagnosa karena sebagian besar penderita pada tahap awal tidak mengalami gangguan penglihatan. Deteksi dini retinopati diabetik pada pasien diabetes merupakan langkah penting untuk mencegah terjadinya kerusakan penglihatan bahkan kebutaan. Gejala awal retinopati diabetik yang dapat dideteksi adalah microaneurysm. Microaneurysm berbentuk titik dan berwarna merah.

Pada penelitian ini akan dikembangkan sistem deteksi dini retinopati diabetik . Berbeda dengan penelitian [4] yang melakukan klasifikasi terhadap fase retinopati diabetik, sistem ini akan mendeteksi gejala awal retinopati diabetik yakni microaneurysm. Algoritma yang digunakan untuk mendeteksi microaneurysm diusulkan oleh [5]. Namun pada penelitian ini akan dilakukan perubahan untuk meningkatkan performa sistem. Sistem akan di uji dengan menggunakan data dari DIARETDB1 dan E-optha untuk mengetahui akurasi, sensitivitas dan spesifitas.

Penelitian yang bertujuan untuk mengembangkan dan menguji sistem deteksi dini retinopati diabetik telah banyak dilakukan oleh peneliti dan akademis dengan media dan metode yang berbeda-beda. Pada penelitan [5] diusulkan algoritma dengan morfologi matematika untuk mendeteksi microaneurysm. Morfologi matematika dipilih karena microaneurysm memiliki bentuk yg khas. Algoritma yang diusulkan ini terdiri dari 3 bagian: pertama preprocessing, kedua mendeteksi kandidat microaneurysm yg ketiga post processing. Performa terbaik algoritma ini adalah ketika green channel, citra fundus mata pada ukuran PAL (720 x 576), ambang batas canny edge detector pada 0.16 , clip limit pada 0.03 dan microaneurysm pada ukuran antara 5 sampai 16 pixel.

Vidya et al.(2011) [6] mengembangkan algoritma untuk menyaring microaneurysm dengan konsep vessel enhancement dengan tujuan untuk mengekstrak struktur dari microaneurysm. Penyaring microanerysm dikembangkan dengan mengubah sigma parameter pada Gaussian filter. Selain untuk mendeteksi microaneurysm algoritma ini juga dapat mendeteksi hemorage yang mana memilliki bentuk yang sama namun memiliki ukuran lebih besar. Algoritma ini memiliki sensitivitas 57,4 \% untuk opthalmologist 1, 35,37\% untuk opthamologist 2 dan $62,687 \%$ untuk opthamologist 3.

Langroudi \& Sadjedi (2010) [7] membuat suatu metode baru yang bertujuan untuk mendeteksi dan mengetahui penyakit retinopati diabetik. Langkah pertama yang dilakukan adalah preprocessing pada gambar retina. Kemudian, optical disk, fovea dan lesion dideteksi. Jenis lesion antara lain microanerysum, hemmorage, soft exudate, hard exudate and drussen yang mana semua jenis lesion ini adalah tanda dari penyakit retinopati diabetik. Jenis lesion ini ditentukan berdasarkan morfologi dari lesion tersebut. Metode yang diusulkan oleh Langroudi dan Sadjedi memiliki sensitifitas 92,5\% dan sepecifitas 81,4\%. Penelitan ini menggunakan citra fundus mata dari database DRIVE dan STARE untuk mengevaluasi hasil.

Kande et al. (2010) [8] membuat metode baru berdasarkan klasifikasi pixel dan morfologi matematika untuk mendeteksi red lesion. Dalam penelitian tersebut pada preprocessing dilakukan histogram matching, histogram matching digunakan untuk memodifikasi histogram komponen kanal hijau menggunakan histogram komponen kanal merah sehingga didapat gambar baru yang memiliki keunggulan dari kedua kanal tersebut. Setelah dilakukan histogram mathching red lesion terlihat jelas dibandingkan sebelumnya. Kemudian untuk mengklasifikasi red lesion digunakan SVM (Support Vector Machine). Metode ini berhasil menurunkan false positif selama ekstraksi kandidat red lesion. Sensitivitas metode ini mencapai $100 \%$ dan spesifitasnya $91 \%$.

Haldar et al. (2016) [9] Mengusulkan menggunakan vessel ekstraksi untuk melakukan perbaikan atau peningkatan citra retina. Peningkatan citra ini dilakukan untuk mengatasi noise

IJCCS Vol. 11, No. 2, July $2017: 209$ - 218 
yang dihasilkan oleh kamera fundus yang menyebabkan dokter sulit untuk mendeteksi kelainan pada citra fundus mata. Usulan tersebut diimplementasikan pada raspberry Pi menggunakan pustaka OpenCV. Rapberry Pi dipilih karena sangat efektif dari segi biaya untuk screening masal retinopati diabetik.

\section{METODE PENELITIAN}

\subsection{Gambaran Sistem}

Sistem deteksi retinopati diabetik ditunjukkan seperti flowchart pada Gambar 1. Suatu gambar fundus akan di deteksi apakah terdapat microaneurysm atau tidak. Jika terdapat microaneurysm maka dianggap positif terkena retinopati diabetik. Namun jika tidak terdapat microaneurysm maka akan dianggap negatif.

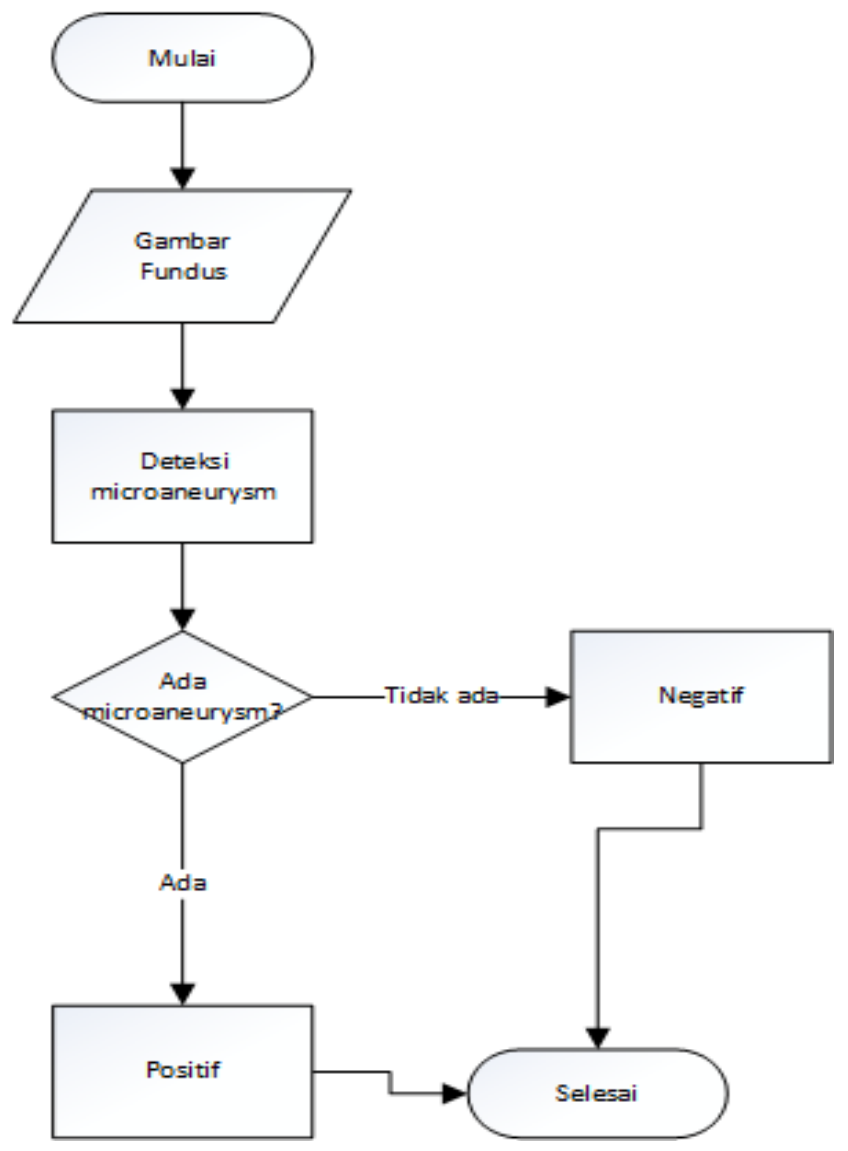

Gambar 1 Flowchart Keseluruhan sistem

Sistem yang dikembangkan akan memproses citra fundus mata kemudian akan dideteksi apakah terdapat microaneurysm. Jika terdapat microaneurysm akan dianggap positif terkena retinopati diabetik begitu juga sebaliknya.

Untuk deteksi microaneurysm akan digunakan algoritma deteksi microaneurysm [5] yang dimodifikasi. Modifikasi dilakukan pada tahap preprocessing yakni dengan menggunakan kanal merah untuk mendeteksi optical disk karena pada kanal tersebut optical disk terlihat jelas [10]. Serta akan dilakukan enhancement dengan menggunakan histogram spesifikasi. Berikut flowchartnya ditunjukkan pada Gambar 2. 


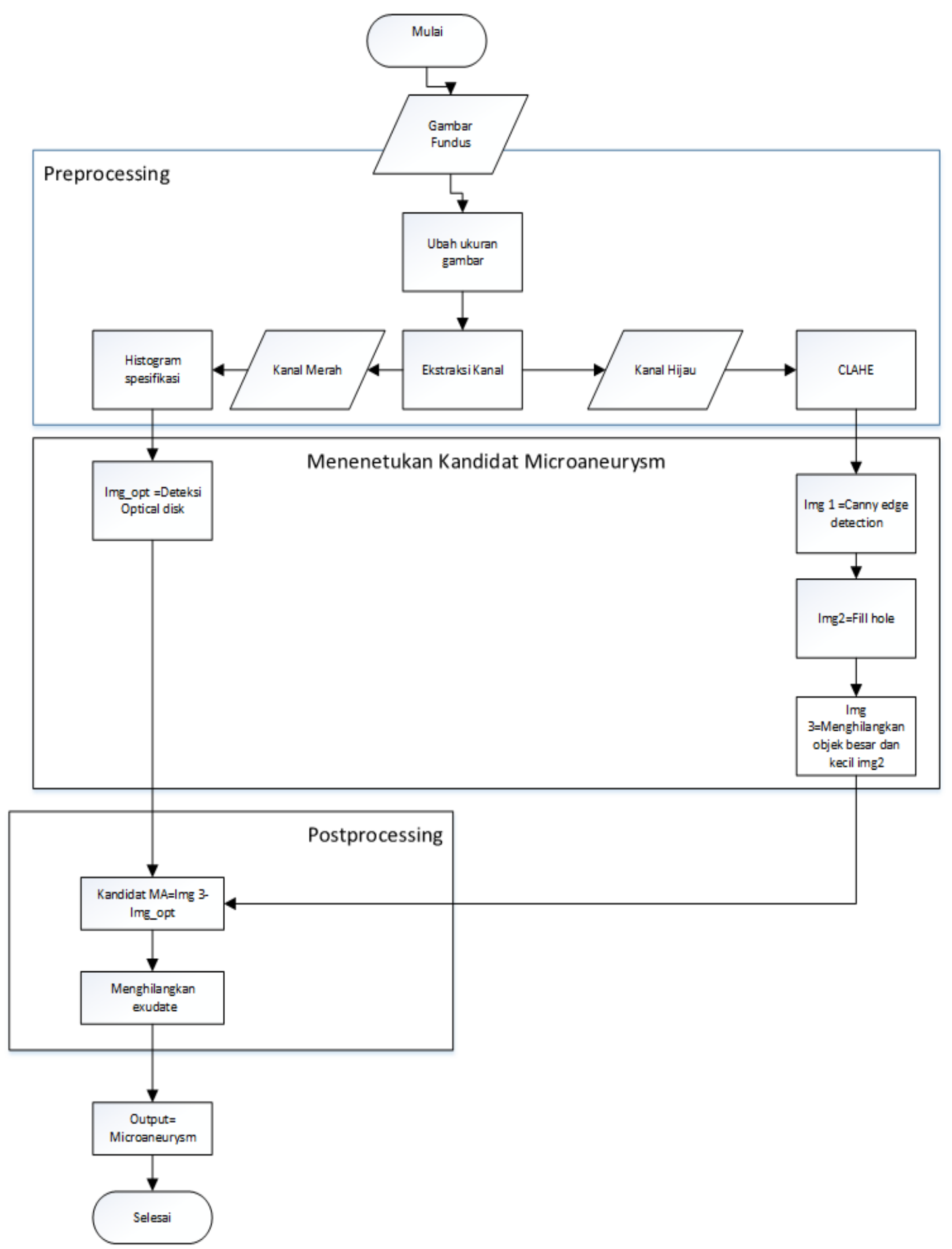

Gambar 2 Algoritma deteksi microaneurysm

\section{2 Implementasi Sistem}

Pada bab ini akan dijelaskan mengenai implementasi sistem, yang meliputi tahapan preprocessing, menemukan kandidat microaneurysm, dan postprocessing. 
Tahap preprocessing bertujuan untuk menyeragamkan mata citra fundus mata sebelum dilakukan proses selanjutnya. Pertama yang dilakukan adalah mengubah ukuran gambar menjadi ukuran PAL (720 x 576). Gambar fundus awal memiliki ukuran (1500 x 1152) pixel dengan 3 kanal (Red,Green,Blue) seperti ditunjukan Gambar 3.

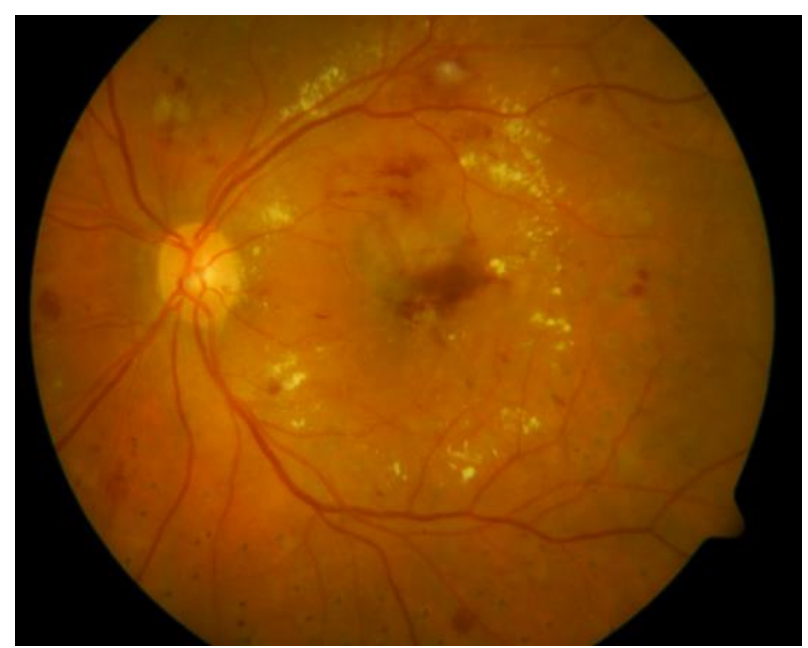

Gambar 3 Gambar fundus awal

Setelah itu dilakuan ekstrasi untuk mendapatkan kanal hijau dan kanal merah. Kemudian setelah itu dilakukan enhancement. CLAHE akan digunakan untuk meningkatkan kanal hijau sedangkan histogram spesifikasi akan digunakan untuk meningkatkan kanal merah. Pada penelitian ini akan diambil gambar fundus pada kanal merah untuk menemukan optical disk karena pada kanal merah optical disk terlihat terlihat terang dibandingkan dengan 2 kanal lainnya. Hasilnya terlihat pada Gambar 4.

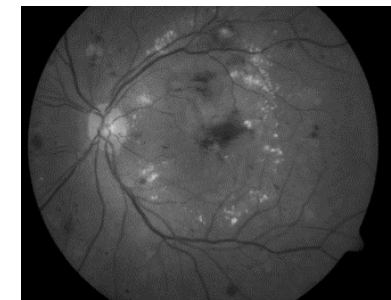

(a)

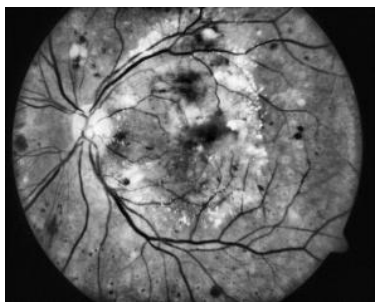

(c)

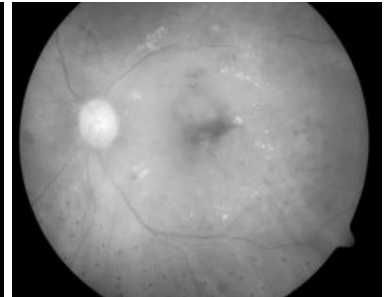

(b)

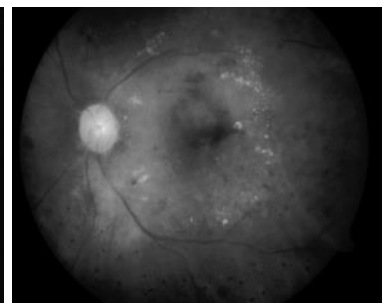

(d)

Gambar 4 (a) Kanal hijau, (b) kanal merah, (c) CLAHE, (d) Histogram spesifikasi 
Tahap berikutnya adalah menemukan kandidat microaneurysm. Tahap ini dilakukan untuk menemukan kandidat microaneurysm dan untuk menemukan optical disk setelah melakukan preprocessing.

Untuk menemukan kandidat microaneurysm yang dilakukan pertama kali adalah melakukan deteksi tepi dengan menggunakan canny edge detector. Hal ini dilakukan untuk mensegmentasi fitur yang terlihat pada Gambar 5(a). Kemudian Gambar 5(a) diisi dengan menggunakan algoritma region filling yang hasilnya terlihat pada Gambar 5(b). Setelah diterapkan algoritma filling akan mucul objek-objek. Setelah itu dilakukan invert seperti pada Gambar 5(c), karena objek yang muncul berwarna hitam maka perlu dikembalikan ke warna sebelumnya supaya dapat diproses pada tahap selanjutnya. Objek yang berukuran besar dan kecil akan dihilangkan. Objek besar merupakan objek yang berukuran lebih besar dari 16px sedangkan objek kecil merupakan objek berukuran kurang dari 5px. Setelah itu baru didapat kandidat microaneurysm terlihat pada Gambar 5(d).

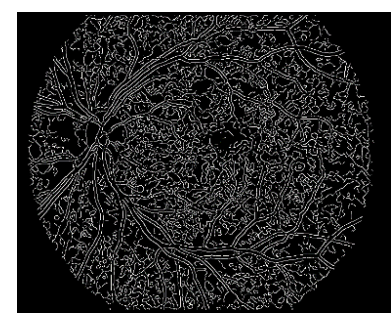

(a)

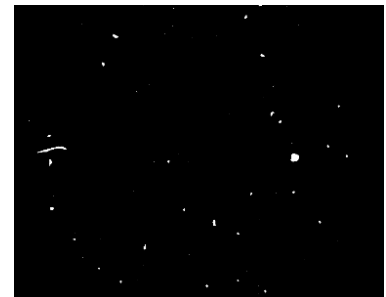

(c)

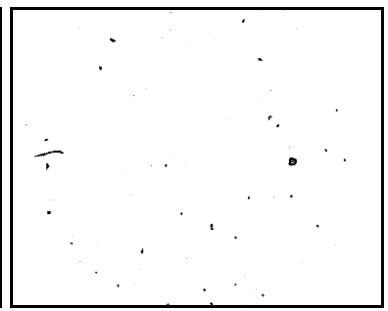

(b)

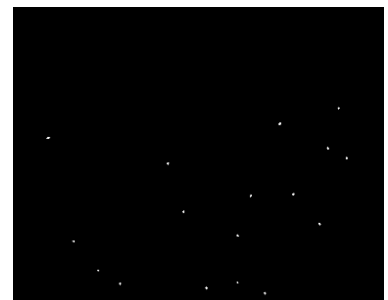

(d)

Gambar 5 (a) Canny edge detection (b) setelah diterapkan flood fill (c) setelah di invert (d) Kandidat microaneurysm

Optical disk perlu ditemukan karena pada tahap postprocesing, optical disk digunakan untuk menghilangkan objek yang terdeteksi. Hal ini dilakukan karena microaneurysm tidak mungkin berada pada optical disk. Jadi jika terdapat objek pada optical disk bukan merupakan microaneurysm.

Untuk menemukan optical disk pada gambar fundus di kanal merah dilakukan enhancement dengan histogram spesifikasi. Setelah itu dilakukan erosi dan dilasi untuk menghilangkan noise .Kemudian dilakukan tresholding untuk menemukan optical disk. Setelah dilakukan tresholding maka akan muncul beberapa objek, untuk menentukan optical disk dipilihlah objek dengan ukuran yang paling besar sebagai optical disk. Flowchart untuk menemukan optical disk ditunjukan pada Gambar 6. 


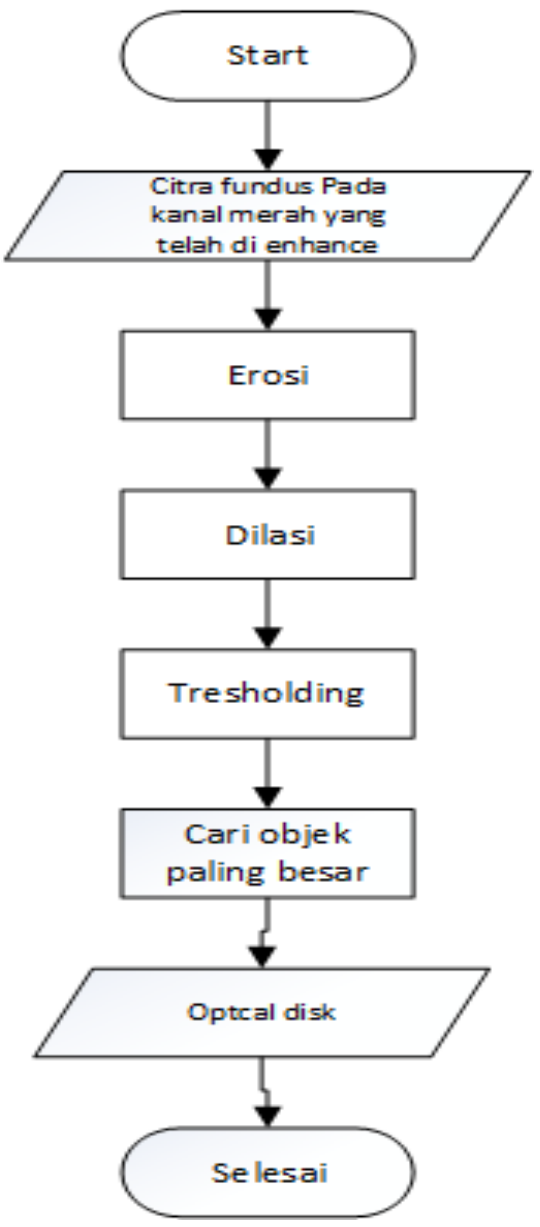

Gambar 6 Flowchart menemukan optical disk

Hasil erosi dan dilasi untuk menghilangkan noise terlihat pada Gambar 7.

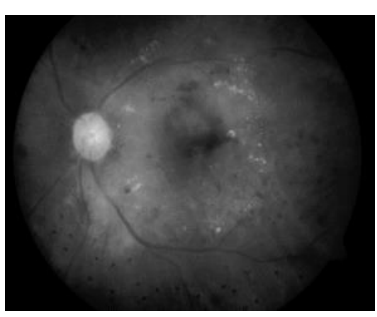

(a)

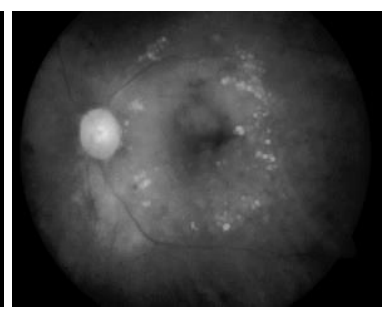

(b)

Gambar 7 (a) erosi (b) dilasi

Selanjutnya dilakukan tresholding. Setelah dilakukan tresholding akan muncul objekobjek. Untuk menentukan optical disk dipilihlah objek dengan ukuran yang paling besar. Terlihat pada Gambar 8. 


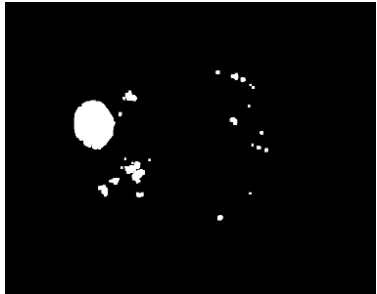

(a)

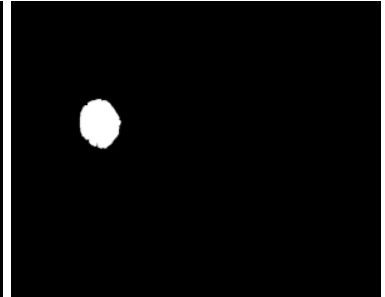

(b)

\section{Gambar 8 (a) Hasil Tresholding), (b) Optical Disk}

Tahap postprocessing dilakukan untuk menghilangkan fitur-fitur yang tidak digunakan seperti optical disk dan exudate. Untuk menghilangkan, yang dilakukan adalah dengan mengurangkan citra terakhir yang didapatkan pada tahap menemukan kandidat microanurysm dengan citra optical disk.Hal ini dilakukan untuk menghilangkan objek yang berada pada optical disk karena microaenurysm tidak mungkin terdapat pada optical disk. Setelah itu menghilangkan exudate, untuk menghilangkan exudate yang dilakukan adalah mengecek kecerahan dari kandidat microaneurysm yang terdeteksi pada kanal hijau citra fundus mata. Karena exudate memiliki bentuk yang khas seperti microaneurysm namun berwarna cerah. Sehingga diperoleh microaneurysm yang sebenarnya. Gambar 9 menunjukkan microaenurysm yang terdeteksi.

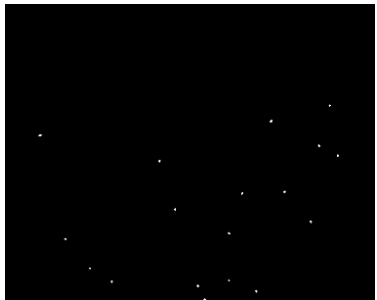

(a)

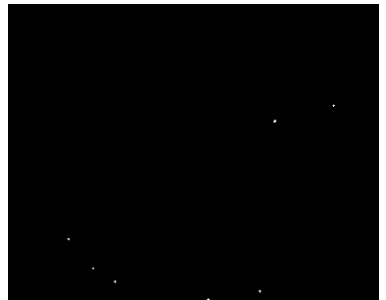

(b)

Gambar 9 (a) Kandidat Microaneurysm (b) Microaneurysm yang terdeteksi

\section{HASIL DAN PEMBAHASAN}

Pada bab ini akan dijelaskan hasil uji coba terhadap sistem yang telah dibangun. Pada penelitian ini digunakan 2 data set untuk menguji sistem. Dataset yang digunakaan adalah DIARETDB1 dan e-optha. Data DIARETB1 yang digunakan sebanyak 89 citra fundus mata. Dalam database ini berisi 89 gambar fundus beserta ground truth yang didapat dari beberapa opthamologists. Gambar fundus yang terdapat pada DIARETDB1 memiliki ukuran 1500 x 1152 pixel. Dari 89 gambar fundus tersebut 84 gambar setidaknya terdapat microaneurysm tanda dari penyakit retinopati diabetik dan 5 dianggap normal dimana tidak terdapat tanda dari penyakit retinopati diabetik.

Dan pada penelitian ini, diambil juga sebanyak 200 citra fundus mata (100 gambar fundus normal dan 100 gambar fundus yang terdapat microaneurysm) dari e-optha. E-optha adalah database gambar fundus berwarna yang didesain khusus untuk penelitian ilmiah retinopati diabetik. E-optha database terdiri dari 148 gambar fundus dengan microaneurysm beserta anotasi yang didapat dari para sepesialis dan 233 gambar fundus normal (sehat). Gambar fundus yang terdapat pada e-optha memiliki ukuran 2544 x 1696 piksel.

Performa sistem akan dilihat berdasarkan akurasi, sensitivitas dan spesifitas dengan perhitungan sebagai berikut: 


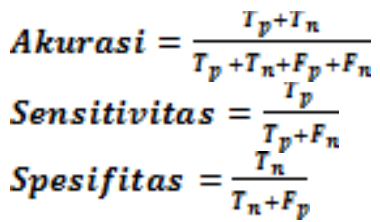

Dimana $T_{p}$ adalah citra fundus mata yang terkena diabetik terdeteksi sebagai retinopati diabetik, $T_{n}$ adalah citra fundus mata yang normal terdeteksi sebagai normal. $\boldsymbol{F}_{\boldsymbol{p}}$ adalah fundus mata yang normal terdeteksi sebagai retinopati diabetik, $\boldsymbol{F}_{n}$ adalah citra fundus mata yang terkena retinopati diabetik sebagai normal. Hasil pengujian ditunjukan pada tabel 1 .

Tabel 1 Akurasi, Sensitivitas, dan Spesifitas

\begin{tabular}{|l|l|l|l|}
\hline Data & Akurasi & Sensitivitas & Spesifisitas \\
\hline DIARETDB1 & $86,51 \%$ & $90 \%$ & $55 \%$ \\
\hline e-optha & $70.5 \%$ & $80 \%$ & $60 \%$ \\
\hline
\end{tabular}

Berdasarkan tabel 1 terlihat bahwa performa dari sistem yang dibuat cukup baik dengan melihat nilai akurasi dan sensitivitas yang cukup tinggi yakni 86,51\% dan $70.5 \%$ untuk akurasi, $90 \%$ dan $80 \%$ untuk sensitivitas. Namun untuk nilai spesifitasnya hanya $55 \%$ dan $60 \%$. Nilai spesifitas yang rendah disebabkan sistem banyak menghasilkan false positif, hal ini dikarenakan terdapat objek yang bukan microaneurysm dianggap oleh sistem sebagai microaneurysm. Objek tersebut dianggap sistem sebagai microaneurysm karena memiliki ukuran dan kecerahan yang sama dengan microaneurysm.

\section{KESIMPULAN}

Sistem yang dibuat memiliki performa yang cukup baik. Pada pengujian dengan data set DIARETDB1 diperoleh hasil akurasi 86,51\%, sensitivitas 90\% dan spesifitas 55\%. Sedangkan pengujian dengan menggunakan data set e-optha diperoleh hasil akurasi $70.5 \%$, sensitivitas $80 \%$ dan spesifitas $60 \%$.

\section{SARAN}

Sistem yang dibuat masih perlu ditingkatkan lagi agar nilai spesifitas yang dihasilkan jauh lebih baik lagi.

\section{UCAPAN TERIMA KASIH}

Penulis mengucapkan terima kasih kepada Departemen Ilmu Komputer dan Elektronika FMIPA UGM yang telah memberikan hibah anggaran untuk penelitian ini.

\section{DAFTAR PUSTAKA}

[1] R. Sitompul, "Retinopati Diabetik," J Indon Med Assoc, vol. 61(8), no. Dm, pp. 337-341, 2011.

[2] K. Noronha and K. P. Nayak, "A Review of Fundus Image Analysis for the Automated Detection of Diabetic Retinopathy," J. Med. Imaging Heal. Informatics, vol. 2, no. 3, pp. 258-265, 2012.

[3] N. Singh and R. C. Tripathi, "Automated Early Detection of Diabetic Retinopathy Using Image Analysis Techniques," Int. J. Comput. Appl., vol. 8, no. 2, pp. 18-23, 2010. 
[4] R. Y. Dillak and A. Harjoko, "Klasifikasi Fase Retinopati Diabetes Menggunakan Backpropagation Neural Network," IJCCS (Indonesian J. Comput. Cybern. Syst., vol. 7, no. 1, pp. 23-34, Jan. 2013 [Online]. Available: https://jurnal.ugm.ac.id/ijccs/article/view/3049. [Accessed: 31-Jul-2017]

[5] A. Purwita and K. Adityowibowo, "Automated Microaneurysm Detection using Mathematical Morphology," Int. Conf. Instrumentation, Commun. Inf. Technol. Biomed. Eng., no. November, pp. 1-4, 2011.

[6] R. Vidyasari, I. Sovani, T. L. R. Mengko, and H. Zakaria, "Vessel enhancement algorithm in digital retinal fundus microaneurysms filter for nonproliferative diabetic retinopathy classification," Proc. - Int. Conf. Instrumentation, Commun. Inf. Technol. Biomed. Eng. 2011, ICICI-BME 2011, no. November, pp. 278-281, 2011.

[7] M. N. Langroudi and H. Sadjedi, "A new method for automatic detection and diagnosis of retinopathy diseases in colour fundus images based on Morphology," Bioinforma. Biomed. Technol. (ICBBT), 2010 Int. Conf., pp. 134-138, 2010.

[8] G. B. Kande, T. S. Savithri, and P. V. Subbaiah, "Automatic detection of microaneurysms and hemorrhages in digital fundus images," J. Digit. Imaging, vol. 23, no. 4, pp. 430-437, 2010.

[9] R. Haldar, S. Aruchamy, A. Chatterjee, and P. Bhattacharjee, "Diabetic Retinopathy Image Enhancement using Vessel Extraction in Retinal Fundus Images by programming in Raspberry Pi Controller Board," pp. 37-42, 2016.

[10] N. Karunanayake, M. Gnanasekera, and N. D. Kodikara, "An Improved Method for Optic Disc Localization,” Int. J. Comput. Appl., vol. 128, no. 13, pp. 975-8887, 2015. 